Perspective

\title{
Shedding Light on a New Psychology of Movement and Exercise
}

\author{
Thibault Deschamps *
}

Nantes Université, Movement - Interactions - Performance, MIP, EA 4334, F-44000 Nantes, France; E-Mail: thibault.deschamps@univ-nantes.fr

* Correspondence: Thibault Deschamps; E-Mail: thibault.deschamps@univ-nantes.fr

Academic Editor: Paul D. Loprinzi

Special Issue: Research of Exercise and Cognitive Function

OBM Integrative and Complementary Medicine 2019, volume 4, issue 3

doi:10.21926/obm.icm.1903055
Received: July 24, 2019

Accepted: September 16, 2019

Published: September 24, 2019

Let's consider the issues of exercise and cognitive function from a different angle, for instance, by moving from a sitting position to standing. Seeing something from different perspectives not only reflects our cognitive flexibility [1] but also has a direct impact on executive performance. Interestingly, some recent studies have reported a smaller Stroop effect when standing than sitting [2-3] or stepping backward [4]. This evidences that body posture enhances selective attention and cognitive control. Through these examples, the assumption presented here is that our daily cognitive functioning is closely linked to our sensorimotor present and vice-versa. Our abilities to move are cognitively vital. Hence a call for a new psychology of movement and, by extension, of exercise emerges [2], with consequences for how to address the role and the effects of movement and exercise on cognitive function.

\section{Movement and Cognition are Intertwined: An Important Illustration in Older Adults}

The understanding of the relationship between age-associated declines in cognitive function, impaired (loco) motor function, and reduced mobility is evolving. These major (pathological) features have generally been viewed as distinct and separate domains for a long time. As a specific

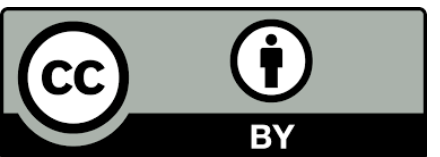

(C) 2019 by the author. This is an open access article distributed under the conditions of the Creative Commons by Attribution License, which permits unrestricted use, distribution, and reproduction in any medium or format, provided the original work is correctly cited. 
example, fall risk in older adults - a major cause of morbidity and mortality [5] - has typically been considered to be unrelated to age-associated changes in cognitive function. However, extensive epidemiological studies have shown that cognition and mobility (and the functional changes underlying the reorganization of the neuro-musculoskeletal system) are intertwined, particularly as the age increases [6]. Thus, older adults with cognitive impairments have been found to have a 10 to 15 times greater risk of developing Alzheimer's disease, as well as a higher risk of gait decline and falls [7-9].

Undoubtedly, thinking, information processing, and moving share behavioral and etiological factors that can evoke further research for the prevention and treatment of these disorders. Mechanistically, brain networks that control movement overlap with the networks involved in the executive performance. For instance, gait slowing and dementia, which often co-exist, have been attributed to the changes in specific brain regions [10-11]. Damage to the microstructural integrity of white matter nerve fibers, whose connections are important for the integration of information from large-scale networks in the brain, is associated with slower walking in older adults and culminates in disorders of cognition, movement, and mood [12-13]. Hence, a challenge that must continue to be addressed concerns the identification of motor signatures that may guide diagnosis and treatment decisions [14-15]. For example, recent studies focusing on such markers have already found that gait control under different (dual-task) conditions could aid in detecting patients with mild cognitive impairment who are at a higher risk of progression to dementia [16], and specific adverse health outcomes (e.g., basic activities of daily life and disability) [17].

\section{Toward a Multidimensional Approach of Individual Cognitive-Motor Functioning}

Besides the fundamental ethical issues that it raises, it would be premature, perhaps presumptuous to say to a person that "show me how you walk, and I will tell your future health outcomes". However, a movement-based approach for clinical and basic research in understanding the cognitive-motor interactions that can affect pathways to disability should involve a "minimum-battery" of tests [18] at different specific, but interconnected, levels of analysis (balance between muscle force, muscular coordination, executive functions and brain activity, and typical signatures in behavioral motor tasks). For example, recent studies have shown that muscle coordination signatures (defined as the distribution of muscle force among individual muscles to produce a locomotor task [19]) can be used with a high accuracy to identify the corresponding individual [20-21], with the assumption that the identification of these individual signatures will ultimately help diagnose and predict the outcomes of musculoskeletal diseases [22]. Hence, an improved individual-level prediction may lead to improved clinical care and clinical trials [23]. It becomes highly intriguing to adopt a more holistic approach to address how the neurocognitive-musculoskeletal system transiently assembles and dismantles its components into functional units to meet task demands, and to better challenge new insights into personalized prevention, management, and rehabilitation of the cognitive and motor impairments in individuals at the risk of developing a chronic condition.

\section{Does a Movement Really Work to Maintain Your Brain?}

The sedentary lifestyle and insufficient participation in physical activity have become a real health problem. Although the positive effects of regular physical activity on the physical and 
mental health and on the prevention of chronic diseases are well documented in the literature [24], the benefits of aerobic-exercise and resistance-training interventions for executive functions are more controversial [25-26]. It can be admitted that the current debate is largely inconclusive but provides promising research opportunities [27-29]. The main starting point that I currently advocate is a new psychology of movement and exercise that would extend beyond a simple and basic physical activity, like walking, cycling or swimming. These activities are necessary (for being physically active, having better aerobic fitness, and gaining health benefits) [30], but are presumably inefficient in maintaining cognitive plasticity and improving executive functions at all stages of life [31-32]. This may look a minor issue but the ability to overcome the impulse not to go for running or to resist the strong urge of not going to swimming, when those physical activities have been planned, even socially declared (such as a New Year resolution, or forced by an old habit), underlines the major interest to challenge and improve the executive functions. This cycle is even more virtuous in that physical activity may facilitate the self-regulation and adoption of positive health behaviors, in addition to a probable exercise-related improvement in executive functions across the whole life span [33-34].

Hence, developing new efficient cognitive enhancement strategies needs to be discussed through the promising concept of (sequential or simultaneous) motor-cognitive training [e.g., 3537]. No one can reasonably imagine the positive effects that might arise by supervised exercise activities on the global cognition or executive function in small groups of "seated" older people at a nursing home. Such supervised simple exercises might include passing a ball to a seatmate, rising from the chair, stepping, or walking a little further. It seems to be still too limited and vastly inefficient, even in the case of high-intensity functional exercise programs [38]. The executive demands are very often insufficient. When considering the cognitive training studies in older adults, in which specific targeted cognitive processes (e.g., working memory) are thought to be boosted using in-house computer programs and video games, some improvements were shown in the trained executive functions, associated with great transferability to untrained skills [39-41]. Beyond the current debate on the robustness of these results (e.g., [42]), the movement control demands are inadequate.

\section{The Relevance of Physical-Cognitive Dual-Task Training}

Movement is more than a mere link between cognition and physical activity; it is the core element with mutual implications. This issue has widely been addressed in the literature through dual-task training [37, 43-44]. For example, specific nonmotor dual-task training has a positive influence on motor control in healthy older adults, as evidenced by significant improvements in postural balance only in the training group [45]. Besides this, several other studies have shown that motor control of daily motor tasks (gait, balance, etc.) depends, at least in part, on executive functions [46-49]. Accordingly, since executive functions are strongly altered in older adults, motor control is impaired, which is manifested by impairments in balance or locomotory tasks [50-51]. Thus, the question arises whether gait and postural control in "unstable" older adults can be improved by training executive functions. Of course, it is possible [45]; however, a different approach, consisting of training cognitive functions through the practice of complex motor skills, has also been proposed. Although this approach is not a novel one [52], the purpose of such a cognitive-motor training program, compared to the classic ones using mental tasks, is to target 
cognitive functions as they are specifically involved in movement control and de facto in physical activities and most sports.

The promising approach of "thinking while moving or moving while thinking" [53] is of major interest from at least two standpoints. First, it would address the cognitive plasticity and executive function issues in a new psychological perspective of movement that is involved at any time [2], rather than assessing the executive measures outside a real daily life context. Second, it reaffirms one of the central purposes in sports sciences, namely, to better understand the sensorimotor mechanisms in relation to executive function. Interestingly, most physical activities and sports meet these "specifications" [see 27 for details]. They require a strong involvement of the executive functions due to the need to keep focusing on what we choose, meanwhile suppressing attention to other stimuli such as not to act impulsively (from the first feint of opponent's attack), to translate instructions (of a coach) to a plan action, to hold information in mind and work with it, and to be flexible enough to adjust efficiently to the changing physical and social environment (e.g., change in strategy of opponents). Inhibition, working memory, and cognitive flexibility are intrinsically essential to meet the changing demands. Hence, investigating the impact of an enhanced cognitively challenging physical activity or an enhanced cognitive training with real motor demands (i.e., combined multi-domain interventions [54-55]) offers promising research opportunities. Let us keep in mind that human beings have not evolved for alighting or resting but for moving [56]; movement is cognitively vital.

In summary, the development of new efficient cognitive enhancement strategies can be addressed by employing the concept of (sequential or simultaneous) motor-cognitive training. Admittedly, some relevant research gaps pertaining to the interaction between everyday movements or physical activity and cognitive plasticity are now better identified. However, concrete knowledge based on research evidence is still required to investigate in-depth, for example, whether the personalized motor-cognitive training-related improvement in executive functions plays a pivotal role in a long-term commitment to physical practice.

\section{Author Contributions}

Drafting of the article: T. Deschamps.

\section{Competing Interests}

The author reports no conflicts of interest.

\section{References}

1. Diamond A. Executive functions. Annu Rev Psychol. 2013; 64: 135-168.

2. Rosenbaum D, Mama Y, Algom D. Stand by your stroop: Standing up enhances selective attention and cognitive control. Psychol Sci. 2017; 28: 1864-1867.

3. Smith KC, Davoli CC, Knapp WH, Abrams RA. Standing enhances cognitive control and alters visual search. Atten Percept Psychophys. 2019. doi: 10.3758/s13414-019-01723-6.

4. Koch S, Holland RW, Hengstler M, van Knippenberg A. Body locomotion as regulatory process: Stepping backward enhances cognitive control. Psychol Sci. 2009; 20: 549-550. 
5. Tinetti ME. Prevention of falls and fall injuries in elderly persons: A research agenda. Prev Med. 1994; 23: 756-762.

6. Montero-Odasso M, Verghese J, Beauchet O, Hausdorff JM. Gait and cognition: A complementary approach to understanding brain function and the risk of falling. J Am Geriatr Soc. 2012; 60: 2127-2136.

7. Boyle PA, Wilson RS, Aggarwal NT, Tang Y, Bennett DA. Mild cognitive impairment: Risk of Alzheimer disease and rate of cognitive decline. Neurology. 2006; 67: 441-445.

8. Mirelman A, Herman T, Brozgol M, Dorfman M, Sprecher E, Schweiger A, et al. Executive function and falls in older adults: New findings from a five-year prospective study link fall risk to cognition. PLoS One. 2012; 7: e40297.

9. Muir SW, Gopaul K, Montero Odasso MM. The role of cognitive impairment in fall risk among older adults: A systematic review and meta-analysis. Age Ageing. 2012; 41: 299-308.

10. Rosano C, Brach J, Longstreth WT, Newman AB. Quantitative measures of gait characteristics indicate prevalence of underlying subclinical structural brain abnormalities in highfunctioning older adults. Neuroepidemiology. 2006; 26: 52-60.

11. Poole VN, Wooten T, Iloputaife I, Milberg W, Esterman M, Lipsitz LA. Compromised prefrontal structure and function are associated with slower walking in older adults. Neuroimage Clin. 2018; 20: 620-626.

12. Rosano C, Aizenstein H, Brach J, Longenberger A, Studenski S, Newman AB. Special article: Gait measures indicate underlying focal gray matter atrophy in the brain of older adults. J Gerontol A Biol Sci Med Sci. 2008; 63: 1380-1388.

13. Tian $Q$, Ferrucci L, Resnick SM, Simonsick EM, Shardell MD, Landman BA, et al. The effect of age and microstructural white matter integrity on lap time variation and fast-paced walking speed. Brain Imaging Behav. 2016; 10: 697-706.

14. Deschamps T. Is psychiatry ready to move? Psychiatry Investig. 2018; 15: 3-5.

15. Mirelman A, Bonato P, Camicioli R, Ellis TD, Giladi N, Hamilton JL, et al. Gait impairments in Parkinson's disease. Lancet Neurol. 2019; 18: 697-708.

16. Montero-Odasso MM, Sarquis-Adamson Y, Speechley M, Borrie MJ, Hachinski VC, Wells J, et al. Association of dual-task gait with incident dementia in mild cognitive impairment: Results from the gait and brain study. JAMA Neurol. 2017; 74: 857-865.

17. Buchman AS, Dawe RJ, Leurgans SE, Curran TA, Truty $T$, Yu L, et al. Different combinations of mobility metrics derived from a wearable sensor are associated with distinct health outcomes in older adults. J Gerontol A Biol Sci Med Sci. 2019. doi: 10.1093/gerona/glz160.

18. Montero-Odasso M, Almeida QJ, Bherer L, Burhan AM, Camicioli R, Doyon J, et al. Consensus on shared measures of mobility and cognition: From the Canadian Consortium on Neurodegeneration in Aging (CCNA). J Gerontol A Biol Sci Med Sci. 2019; 74: 897-909.

19. Hug F, Goupille C, Baum D, Raiteri BJ, Hodges PW, Tucker K. Nature of the coupling between neural drive and force-generating capacity in the human quadriceps muscle. Proc Biol Sci. 2015. doi: 10.1098/rspb.2015.1908.

20. Crouzier M, Hug F, Dorel S, Deschamps T, Tucker K, Lacourpaille L. Do individual differences in the distribution of activation between synergist muscles reflect individual strategies? Exp Brain Res. 2019; 237: 625-635. 
21. Horst F, Mildner M, Schöllhorn WI. One-year persistence of individual gait patterns identified in a follow-up study - A call for individualised diagnose and therapy. Gait Posture. 2017; 58: 476-480.

22. Hug F, Tucker K. Muscle coordination and the development of musculoskeletal disorders. Exerc Sport Sci Rev. 2017; 45: 201-208.

23. Iddi S, Li D, Aisen PS, Rafii MS, Thompson WK, Donohue MC, et al. Predicting the course of Alzheimer's progression. Brain Inform. 2019; 6: 6.

24. Warburton DER, Nicol CW, Bredin SSD. Health benefits of physical activity: The evidence. CMAJ. 2006; 174: 801-809.

25. Soga K, Masaki H, Gerber M, Ludyga S. Acute and long-term effects of resistance training on executive function. J Cogn Enhanc. 2018; 2: 200-207.

26. Wilke J, Giesche F, Klier K, Vogt L, Herrmann E, Banzer W. Acute effects of resistance exercise on cognitive function in healthy adults: A systematic review with multilevel meta-analysis. Sports Med. 2019; 49: 905-916.

27. Diamond A, Ling DS. Conclusions about interventions, programs, and approaches for improving executive functions that appear justified and those that, despite much hype, do not. Dev Cogn Neurosci. 2016; 18: 34-48.

28. Diamond A, Ling DS. Aerobic-Exercise and resistance-training interventions have been among the least effective ways to improve executive functions of any method tried thus far. Dev Cogn Neurosci. 2019; 37: 100572.

29. Hillman $\mathrm{CH}$, McAuley $\mathrm{E}$, Erickson $\mathrm{KI}$, Liu-Ambrose $\mathrm{T}$, Kramer AF. On mindful and mindless physical activity and executive function: A response to Diamond and Ling (2016). Dev Cogn Neurosci. 2019; 37: 100529.

30. Yaffe K, Barnes D, Nevitt M, Lui LY, Covinsky K. A prospective study of physical activity and cognitive decline in elderly women: Women who walk. Arch Intern Med. 2001; 161: 17031708.

31. Northey JM, Cherbuin N, Pumpa KL, Smee DJ, Rattray B. Exercise interventions for cognitive function in adults older than 50: A systematic review with meta-analysis. Br J Sports Med. 2018; 52: 154-160.

32. Singh AS, Saliasi E, van den Berg V, Uijtdewilligen L, de Groot RHM, Jolles J, et al. Effects of physical activity interventions on cognitive and academic performance in children and adolescents: A novel combination of a systematic review and recommendations from an expert panel. Br J Sports Med. 2019; 53: 640-647.

33. Daly M, McMinn D, Allan JL. A bidirectional relationship between physical activity and executive function in older adults. Front Hum Neurosci. 2014; 8: 1044.

34. Loprinzi PD. Physical activity is the best buy in medicine, but perhaps for less obvious reasons. Prev Med. 2015; 75: 23-24.

35. Bherer L. Cognitive plasticity in older adults: Effects of cognitive training and physical exercise. Ann N Y Acad Sci. 2015; 1337: 1-6.

36. Falck RS, Davis JC, Best JR, Crockett RA, Liu-Ambrose T. Impact of exercise training on physical and cognitive function among older adults: A systematic review and meta-analysis. Neurobiol Aging. 2019; 79: 119-130. 
37. Li KZH, Bherer L, Mirelman A, Maidan I, Hausdorff JM. Cognitive Involvement in balance, gait and dual-tasking in aging: $A$ focused review from a neuroscience of aging perspective. Front Neurol. 2018; 9: 913.

38. Toots A, Littbrand H, Boström G, Hörnsten C, Holmberg H, Lundin-Olsson L, et al. Effects of exercise on cognitive function in older people with dementia: A randomized controlled trial. J Alzheimers Dis. 2017; 60: 323-332.

39. Dahlin E, Neely AS, Larsson A, Bäckman L, Nyberg L. Transfer of learning after updating training mediated by the striatum. Science. 2008; 320: 1510-1512.

40. Hertzog C, Kramer AF, Wilson RS, Lindenberger U. Enrichment effects on adult cognitive development: Can the functional capacity of older adults be preserved and enhanced? Psychol Sci Public Interest. 2008; 9: 1-65.

41. Karbach J, Kray J. How useful is executive control training? Age differences in near and far transfer of task-switching training. Dev Sci. 2009; 12: 978-990.

42. Teixeira-Santos AC, Moreira CS, Magalhães R, Magalhães C, Pereira DR, Leite J, et al. Reviewing working memory training gains in healthy older adults: A meta-analytic review of transfer for cognitive outcomes. Neurosci Biobehav Rev. 2019; 103: 163-177.

43. Falbo S, Condello G, Capranica L, Forte R, Pesce C. Effects of physical-cognitive dual task training on executive function and gait performance in older adults: A randomized controlled trial. Biomed Res Int. 2016; 2016: 5812092.

44. Oliveira AS, Reiche MS, Vinescu Cl, Thisted SAH, Hedberg C, Castro MN, et al. The cognitive complexity of concurrent cognitive-motor tasks reveals age-related deficits in motor performance. Sci Rep. 2018; 8: 6094.

45. Li KZH, Roudaia E, Lussier M, Bherer L, Leroux A, McKinley PA. Benefits of cognitive dual-task training on balance performance in healthy older adults. J Gerontol A Biol Sci Med Sci. 2010; 65: 1344-1352.

46. Boisgontier MP, Beets IAM, Duysens J, Nieuwboer A, Krampe RT, Swinnen SP. Age-related differences in attentional cost associated with postural dual tasks: Increased recruitment of generic cognitive resources in older adults. Neurosci Biobehav Rev. 2013; 37: 1824-1837.

47. Dalton C, Sciadas R, Nantel J. Executive function is necessary for the regulation of the stepping activity when stepping in place in older adults. Aging Clin Exp Res. 2016; 28: 909-915.

48. Vaughan L, Giovanello K. Executive function in daily life: Age-related influences of executive processes on instrumental activities of daily living. Psychol Aging. 2010; 25: 343-355.

49. Yogev-Seligmann G, Hausdorff JM, Giladi N. The role of executive function and attention in gait. Mov Disord. 2008; 23: 329-342.

50. Beauchet O, Launay CP, Fantino B, Annweiler C, Allali G. Episodic memory and executive function impairments in non-demented older adults: Which are the respective and combined effects on gait performances? Age. 2015; 37: 9812.

51. Deschamps T, Beauchet O, Annweiler C, Cornu C, Mignardot J-B. Postural control and cognitive decline in older adults: Position versus velocity implicit motor strategy. Gait Posture. 2014; 39: 628-630.

52. Voelcker-Rehage C, Godde B, Staudinger UM. Physical and motor fitness are both related to cognition in old age. Eur J Neurosci. 2010; 31: 167-176. 
53. Herold F, Hamacher D, Schega L, Müller NG. Thinking while moving or moving while thinking concepts of motor-cognitive training for cognitive performance enhancement. Front Aging Neurosci. 2018; 10: 228.

54. Ballesteros S, Voelcker-Rehage C, Bherer L. Editorial: Cognitive and brain plasticity induced by physical exercise, cognitive training, video games, and combined interventions. Front Hum Neurosci. 2018; 12: 169.

55. Pothier K, Gagnon C, Fraser SA, Lussier M, Desjardins-Crépeau L, Berryman N, et al. A comparison of the impact of physical exercise, cognitive training and combined intervention on spontaneous walking speed in older adults. Aging Clin Exp Res. 2018; 30: 921-925.

56. Arem H, Moore SC, Patel A, Hartge P, Berrington de Gonzalez A, Visvanathan $K$, et al. Leisure time physical activity and mortality: $A$ detailed pooled analysis of the dose-response relationship. JAMA Intern Med. 2015; 175: 959-967.

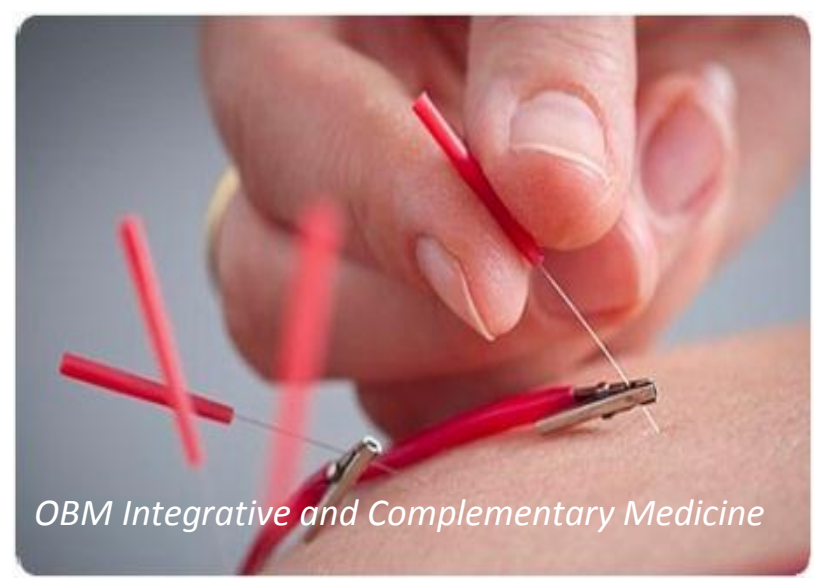

Enjoy OBM Integrative and Complementary Medicine by:

1. Submitting a manuscript

2. Joining in volunteer reviewer bank

3. Joining Editorial Board

4. Guest editing a special issue

For more details, please visit: http://www.lidsen.com/journals/icm 